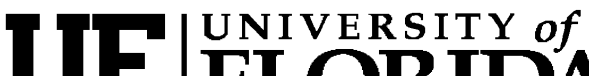 FLORIDA \\ IFAS Extension
}

FOR 128

\section{Urban Forests in Florida: Do They Reduce Air Pollution?1}

\section{Francisco Escobedo ${ }^{2}$}

Can trees influence the environmental quality of Florida's cities and the well-being of their inhabitants? Several studies have demonstrated that trees can affect air quality and alter the energy used for cooling and heating of buildings. In this fact sheet I will present the factors behind pollution removal by trees, estimate the amount of air pollution removal for three Florida cities, and finally present some general strategies for managing urban trees for air quality improvement.

The trees that make up an urban forest can influence local air quality by directly removing air pollutants and indirectly modifying microclimates through lowering temperature, and altering wind patterns. In general, air pollution is removed from the atmosphere in three ways: through deposition, precipitation, and wind. Through a process called dry deposition, pollutants near tree canopies settle on, and adhere to, leaf surfaces. Particulate matter in the air is deposited on leaves due to gravity and wind movements. Particles that remain on the leaf surface can be re-suspended to the atmosphere by wind, washed off by precipitation, or deposited on the ground through leaf and twig fall. When gaseous pollutants are deposited on tree leaves, they can be absorbed on the leaf surface or diffused into the leaves through tiny leaf surface openings called stomata.

Shading and transpiration from trees can affect the overall microclimate of an area by modifying ambient temperature and solar radiation, wind patterns, and relative humidity. These changes in microclimate also affect local pollution concentrations. In most cases transpiration and shading from trees reduce summertime temperatures, which may reduce the amount of energy used to cool buildings. Likewise, with properly placed trees, a windbreak can reduce cold air coming into a structure while allowing solar heating during the winter. Collectively, if less energy is used for heating and cooling, fewer greenhouse gases are emitted from power plants.

In some cases though, the microclimate can be changed in a negative way. For example, scattered tree can allow radiation to heat the ground while also reducing wind flows. In this situation wind is prevented from cooling these areas and pollutants might become trapped under the tree canopy. So, it becomes important to know the wind patterns of an area and how planting trees may influence that pattern.

1. This is document FOR 128, one of a series of the School of Forest Resources and Conservation, Florida Cooperative Extension Services, Institute of Food and Agricultural Sciences, University of Florida. First published: October 2007. Please visit the EDIS Web site at http://edis.ifas.ufl.edu.

2. Francisco Escobedo, Assistant Professor, School of Forest Resources and Conservation, Cooperative Extension Service, Institute of Food and Agricultural Sciences, University of Florida, Gainesville, FL 32611.

The Institute of Food and Agricultural Sciences (IFAS) is an Equal Opportunity Institution authorized to provide research, educational information and other services only to individuals and institutions that function with non-discrimination with respect to race, creed, color, religion, age, disability, sex, sexual orientation, marital status, national origin, political opinions or affiliations. U.S. Department of Agriculture, Cooperative Extension Service, University of Florida, IFAS, Florida A. \& M. University Cooperative Extension Program, and Boards of County Commissioners Cooperating. Larry Arrington, Dean 
Natural compounds called volatile organic compounds are produced from certain trees in high temperatures during the summer. These compounds can affect air quality by reacting with existing pollution under certain climatic conditions to form smog. Through shading though, trees can reduce ambient temperatures thus reducing the likelihood of smog being formed. Finally, mechanical tree maintenance activities that use gas or diesel such as vehicles, chainsaws, chippers, leaf blowers, etc can also contribute heat and emit pollutants in a city.

Researchers from the USDA Forest Service recently used a computer model called Urban Forest Effects (UFORE) to estimate the amount of air pollution removal by urban forests in Jacksonville, Tampa, and Miami, Florida (Table 1). Air pollutants removed included particulate matter less than 10 microns, ozone, nitrogen dioxide, sulfur dioxide, and carbon monoxide. Jacksonville's urban forest had the highest total pollution removal of any city in Florida and for the entire United States. However, this was due to the large land area included in the city limits $\left(759 \mathrm{mi}^{2}\right)$ and a high estimated tree cover of $53 \%$ and not its pollution removal rate. Jacksonville's pollution removal rate per unit of tree cover was lower than Miami's and Tampa's. The study assumed Miami had a $3.7 \%$ tree cover and that Tampa had a $10 \%$ tree cover. Overall air quality improvement in Tampa was approximately $1 \%$.

If we assume that Jacksonville can be used to estimate the pollution removal rate of urban forests in north Florida, Tampa for central portions of the state, and Miami for south Florida, we can calculate the total pollution removed for a city or a site by its tree cover. For example, if we assume that 1 -acre parks in north, central, and south Florida have 25\% tree cover we can estimate that 24,32 , and 28 pounds of pollutants are removed, respectively.

Other arboriculture and urban and community forest management objectives need to be considered alongside improving air quality, but in general, the following strategies can be used to design and manage urban forests to improve air quality in Florida:

- Greater tree cover will result in increased pollution removal;
- Dense evergreen canopies are better than sparse deciduous canopies for particulate matter removal;

- The greater the precipitation in a given area, the lower the pollution removal ability of trees for that area (in this case pollution is removed by precipitation);

- The less maintenance is required for a tree, the better that tree's contribution is for air pollution removal (use low maintenance trees and reduce gas or diesel use);

- Longer-lived trees will provide more pollution removal for a longer period of time;

- Plant trees in places that will provide summertime cooling for buildings and cars, and solar heating during the winter;

- Plant trees in highly urbanized areas with pollution problems; trees will remove more pollution in areas with higher pollution concentrations;

- Avoid using trees that are not resistant to air pollution.

\section{Further Readings}

Chameides, W.L., Lindsay, R.W., Richardson J., and C.S. Kiang. 1988. The role of biogenic hydrocarbons in urban photochemical smog: Atlanta as a case study. Science 241: 1473-1475.

McPherson, E.G. and J.R. Simpson. 1999. Carbon Dioxide Reduction Through Urban Forestry: Guidelines for Professional and Volunteer Planters. Gen. Tech Rep. PSW GTR-17. Albany, CA: Pacific Southwest Research Station, U.S. Department of Agriculture Forest Service. 237 p.

Nowak, D.J., Crane D.E. and J. Stevens. 2006. Air pollution removal by urban trees and shrubs in the United States. Urban Forestry and Urban Greening, 4: 115-123.

Scott, K.I.; Simpson, J.R.; E.G. McPherson. 1999. Effects of tree cover on parking lot microclimate and vehicle emissions. Journal of Arboriculture. 25(3): 129-142. 
Smith, W.H. 1990. Air Pollution and Forests.

New York: Springer-Verlag. 618 p.

Table 1. Pollution removal in 3 Florida urban forests.

\begin{tabular}{||l|l|c||}
\hline \hline City & $\begin{array}{l}\text { Pollution Removal Rate } \\
\text { (pounds per acre of tree } \\
\text { cover) }\end{array}$ & $\begin{array}{l}\text { Total Pollution } \\
\text { (tons removed) }\end{array}$ \\
\hline Jacksonville & 95 & 12,236 \\
\hline Tampa & 127 & 424 \\
\hline Miami & 113 & 268 \\
\hline \multicolumn{2}{|l|}{ Source: Nowak, D.J, Crane D.E., and J. Stevens. 2006. } \\
\hline \multicolumn{2}{|l}{} \\
\hline
\end{tabular}

